\title{
Eribulin mesylate in patients with refractory cancers: a Phase I study
}

\author{
Toru Mukohara $\cdot$ Shunji Nagai $\cdot$ Hirofumi Mukai $\cdot$ \\ Masayuki Namiki • Hironobu Minami
}

Received: 17 June 2011 / Accepted: 17 August 2011 /Published online: 2 September 2011

(C) The Author(s) 2011. This article is published with open access at Springerlink.com

\begin{abstract}
Summary Eribulin mesylate (Halaven ${ }^{\mathrm{TM}}$, E7389) is a synthetic analog of the marine natural product halichondrin B that acts via a mechanism distinct from conventional tubulintargeted agents. This Phase I study (clinicaltrials.gov identifier: NCT00326950) was the first to investigate eribulin mesylate in Japanese patients. The study determined the recommended dose, MTD, DLTs, safety, pharmacokinetics, and antitumor activity of eribulin administered on Days 1 and 8 of a 21-day cycle in Japanese patients with advanced solid tumors. Fifteen patients received eribulin mesylate $0.7-2.0 \mathrm{mg} / \mathrm{m}^{2}$ as a 2 - to $10-\mathrm{min}$ intravenous injection. Neutropenia was the principal DLT. DLTs were observed in two of six patients treated at $1.4 \mathrm{mg} / \mathrm{m}^{2}$, and in all three patients at $2.0 \mathrm{mg} / \mathrm{m}^{2}$. The recommended dose was $1.4 \mathrm{mg} / \mathrm{m}^{2}$ and the MTD was $2.0 \mathrm{mg} / \mathrm{m}^{2}$. Neutropenia (67\%), lymphocytopenia (20\%), febrile neutropenia (33\%), and fatigue $(13 \%)$ were the most common grade 3 or 4
\end{abstract}

Presented in poster format at the 20th EORTC-NCI-AACR symposium on Molecular Targets and Cancer Therapeutics, Geneva, Switzerland, 21-24 October 2008.

T. Mukohara $\cdot$ H. Minami $(\bowtie)$

Medical Oncology/Hematology,

Kobe University Hospital and Graduate School of Medicine,

7-5-1 Kusunoki-cho, Chuo-ku,

Kobe 650-0017, Japan

e-mail: hminami@med.kobe-u.ac.jp

S. Nagai $\cdot$ H. Mukai

Division of Oncology/Hematology,

National Cancer Center Hospital East,

6-5-1 Kashiwanoha, Kashiwa,

Chiba 277-8577, Japan

\section{Namiki}

Japan Clinical Pharmacology, Eisai Co., Ltd,

Koishikawa 4-6-10, Bunkyo-ku,

Tokyo 112-8088, Japan toxicities. Eribulin exhibited triphasic pharmacokinetics with a long terminal half-life, high volume of distribution, and low urinary clearance. Three patients achieved partial responses (two with NSCLC, one with head and neck cancer) at $1.4 \mathrm{mg} / \mathrm{m}^{2}$ dose level. Eribulin mesylate, administered on Days 1 and 8 of a 21-day cycle, exhibits manageable tolerability at $1.4 \mathrm{mg} / \mathrm{m}^{2}$. DLT was neutropenia.

Keywords Eribulin mesylate - Japanese patients · Phase I . Pharmacodynamics $\cdot$ Pharmacokinetics

\section{Introduction}

Eribulin mesylate (Halaven ${ }^{\mathrm{TM}}$, E7389), a non-taxane microtubule dynamics inhibitor, is a structurally simplified synthetic analog of the marine natural product halichondrin B [1,2]. Inhibition of microtubule dynamics by eribulin is achieved via a novel mechanism of action distinct from other antitubulin agents [3, 4], probably involving eribulin binding to a unique site on tubulin [5]. Eribulin's inhibitory effects on microtubule dynamics lead to G2/M cell cycle blocks, disruption of normal mitotic spindle formation and, following prolonged mitotic blockage, apoptotic cell death $[1,2]$. In preclinical studies, eribulin has been shown to elicit potent anticancer effects in a variety of cell-based and animal models of human cancers, including wellestablished human tumor xenograft models derived from breast, colon, melanoma, and ovarian cancer [2].

Three Phase I studies have previously investigated different dosing schedules for eribulin mesylate in patients with advanced solid tumors. The first study determined a recommended dose (RD) for Phase II studies of $1.4 \mathrm{mg} / \mathrm{m}^{2}$ when eribulin mesylate was administered as a 1- to 2-min intravenous (i.v.) bolus on Days 1, 8, and 15 of a 28-day 
cycle [6]. When eribulin mesylate was administered as a 1 -h infusion according to the same treatment schedule as the first study, the RD was $1.0 \mathrm{mg} / \mathrm{m}^{2}$ [7]. In the third study, in which eribulin mesylate was administered as a 1 -h infusion every 21 days, the RD was found to be $2.0 \mathrm{mg} / \mathrm{m}^{2}$ [8]. In all three studies, neutropenia was reported as the most common dose-limiting toxicity (DLT).

When the present study was planned, two Phase II studies were ongoing in metastatic breast cancer (MBC) and non-small cell lung cancer (NSCLC). The Phase II study in MBC initially investigated eribulin mesylate $1.4 \mathrm{mg} / \mathrm{m}^{2}$ as a 2- to 5-min i.v. infusion on Days 1,8 , and 15 of a 28-day cycle [9], based on the results of the first Phase I study in which omission of the Day 15 administration was not included as a DLT [6]. However, $63 \%$ of patients (44/70) experienced dose delays associated with neutropenia during the first cycle, resulting in omission of the Day 15 dose. Therefore, the schedule was modified to a 2- to 5-min i.v. infusion administered on Days 1 and 8 of a 21-day cycle. In the Phase II study in NSCLC, hematologic toxicities caused several patients to experience dose interruptions, delays, or omissions when eribulin mesylate $1.4 \mathrm{mg} / \mathrm{m}^{2}$ was administered on Days 1,8 , and 15 of a 28-day cycle. The dosing schedule was again changed to Days 1 and 8 of a 21-day cycle [10]. However, an optimal dose of eribulin mesylate administered on Days 1 and 8 of a 21-day cycle has not been determined in a formal Phase I study. Therefore, administration of eribulin at doses higher than those used in previous studies may be possible, although the safety profile of eribulin at the recommended Phase II dose seemed to be tolerable.

On the basis of these findings, the present study was planned to be the first Phase I study to investigate if higher doses of eribulin mesylate i.v. injection administered on Days 1 and 8 of a 21-day cycle could be given [6-8]. The objectives were to determine the RD, MTD and DLT of eribulin mesylate in this dosing schedule, and safety, tolerability, pharmacokinetic (PK) profile, as well as tumor response, were also assessed.

\section{Materials and methods}

Study design and patient selection

This was a single-center, non-randomized, open-label, doseescalation Phase I study of eribulin in Japanese patients with advanced solid tumors. Eligibility criteria included: 20-74 years of age; histologically or cytologically confirmed locally advanced solid malignancies that had either failed to respond or had progressed following standard therapy, or for whom no other treatment options were available; an Eastern Cooperative Oncology Group perfor- mance status of 0 or 1 ; a life expectancy of at least 3 months; no ongoing adverse drug reactions (ADRs) (excluding alopecia) to prior therapy, and adequate function of all major organs (including bone marrow, liver, kidney, and lungs).

Patients were excluded from the study if they had received chemotherapy or investigational drug therapy within 4 weeks prior to study initiation (exceptions to this were 6 weeks for nitrosoureas or 2 weeks for radio-, endocrine-, or immunotherapy). Additional exclusion criteria included: women who were pregnant or breastfeeding; those who required continuous systemic steroid therapy or extensive radiotherapy; patients who tested positive for HIV, hepatitis $\mathrm{C}$ virus antibody, or hepatitis B virus surface antigen; the presence of systemic infection (fever $\geq 38^{\circ} \mathrm{C}$ ); pleural effusion or ascites; brain metastases; serious complications, which included medically uncontrolled cardiovascular illness, hepatic cirrhosis, interstitial pneumonia or pulmonary fibrosis, or a history of bleeding disorders.

The protocol was approved by the Institutional Review Board and conducted in accordance with the Declaration of Helsinki. All patients provided written informed consent prior to any study procedure and were required to remain in the hospital from the start of eribulin treatment to completion of the first cycle.

\section{Eribulin treatment and concomitant medication}

Patients received a 2- to $10-\mathrm{min}$ i.v. injection of eribulin on Days 1 and 8 of a 21-day cycle. The initial dose level of eribulin mesylate was $0.7 \mathrm{mg} / \mathrm{m}^{2}$, with planned dose levels of $1.0 \mathrm{mg} / \mathrm{m}^{2}, 1.4 \mathrm{mg} / \mathrm{m}^{2}$, and $2.0 \mathrm{mg} / \mathrm{m}^{2}$ administered sequentially following safety evaluation of the $0.7 \mathrm{mg} / \mathrm{m}^{2}$ dose. Cohorts of three to six patients were planned to receive eribulin at each of the dose levels. After one cycle of eribulin, a one-level dose escalation occurred if no DLTs were observed in a group of three patients. For cases in which DLTs were observed in one of three patients, an additional three patients were added to the dose-level cohort. A one-level dose escalation occurred if only one of six patients experienced a DLT. In the event that two of six patients reported a DLT, the investigators obtained either written or verbal advice from an independent efficacy and safety committee on whether to increase or decrease the dose level of eribulin in that cohort. The dose level was not increased if a DLT was reported in three or more patients. Patients continued to receive eribulin until they no longer received clinical benefit, had progressive disease, or experienced unacceptable toxicity.

Concomitant use of other medications or treatments was allowed. However, as eribulin is a substrate for CYP3A4 [11], treatment with drugs that are known CYP3A4 
inhibitors (itraconazole, erythromycin, clarithromycin, and diltiazem) were not permitted due to the potential for drugdrug interactions. Similarly, foods containing St John's Wort (Hypericum perforatum) and some medications (rifampicin, carbamazepine, phenobarbital, phenytoin) were also not allowed due to their ability to induce CYP3A4. Other investigational drugs and preventive administration of granulocyte-colony stimulating factor were not permitted during the study.

\section{Clinical assessments}

\section{Safety, DLT, and MTD}

Demographic and disease characteristics recorded at baseline included clinical diagnosis, tumor cell and tissue type, and prior therapy complications. Safety assessments, performed on all patients receiving at least one dose of eribulin, were made throughout the study. These included adverse events (AEs), ADRs, vital signs, bodyweight, 12-lead electrocardiogram, chest $\mathrm{X}$-ray, concomitant medications, and establishment of clinical laboratory values (hematology, blood biochemistry, urinalysis).

Assessments of AEs and ADRs were made on Days 1, 8, 15 , and 21 of each cycle. AE severity was classified according to the Japanese version of Common Terminology Criteria for Adverse Events v3.0 [12].

ADRs which are relevant to any of the following three different criteria were defined as a DLT: (i) hematologic toxicity, which included grade 4 neutropenia defined as $<500 / \mathrm{mm}^{3}$ and continuing for 5 days or more, $\geq$ grade 3 neutropenia requiring i.v. antibiotic therapy, febrile neutropenia, or grade 4 thrombocytopenia defined as $<25,000 / \mathrm{mm}^{3}$; (ii) non-hematologic toxicity $\geq$ grade 3 , excluding nausea, vomiting, anorexia, and electrolyte abnormality with no clinical symptoms; (iii) omission of the Day 8 dose within a cycle due to the occurrence of $\geq$ grade 3 neutropenia defined as $<1,000 / \mathrm{mm}^{3}$, $\geq$ grade 3 thrombocytopenia defined as $<50,000 / \mathrm{mm}^{3}$, or investigator decision to skip the administration. If Day 8 administration was omitted during the first cycle because of non-hematologic AEs unrelated to eribulin treatment, this was not classified as a DLT, and one patient was added at the same dose level. The MTD was defined as the lowest dose at which a DLT occurred in either two or three of three patients, or in $\geq 3$ of five or six patients during the first cycle.

PK and biochemical methodology

Plasma samples were taken for PK analysis on Days 1 and 8 of the first treatment cycle, pre-dose, end of infusion, and
5, 15, and $30 \mathrm{~min}$, and $1,2,4,8,24,48,72$, and $168 \mathrm{~h}$ after drug administration. Urine samples were collected pre-dose and within 24,48 , and $72 \mathrm{~h}$ after the start of the injection on Day 1 of cycle 1 .

Concentrations of eribulin, measured as the free-base (i.e. non-mesylate) equivalent, were determined in both plasma and urine following separation of eribulin from ER-076349 (internal standard) using validated liquid chromatography/mass spectrometry methods [7, 13]. Plasma eribulin concentration versus time data were calculated by a non-compartmental approach using WinNonlin software version 5.2 (Pharsight Corporation, Mountain View, CA). The amount and percent of the eribulin dose recovered in urine were also calculated.

The relationships between the maximum plasma concentration $\left(\mathrm{C}_{\max }\right)$ or area under the concentration-time curve from time zero to last measurable concentration $\left(\mathrm{AUC}_{0-\mathrm{t}}\right)$ and the nadir of hematologic values (white blood cell count, neutrophil count, lymphocyte count, red blood cell count, hemoglobin concentration, and platelet count) or the change in hematologic values from baseline were evaluated using a sigmoid maximum effect $\left(\mathrm{E}_{\max }\right)$ model.

\section{Tumor assessment}

Tumor measurements, to evaluate primary lesions, metastatic lesions, and the presence/absence of new lesions, were performed at baseline and every 6 weeks in accordance with Response Evaluation Criteria in Solid Tumors (RECIST) [14].

\section{Results}

Patient characteristics

This study was initiated on May 19, 2006, and completed on January 8, 2008. Fifteen patients received eribulin mesylate at one of four dose levels. These patients had various primary tumor types and were extensively pretreated with a median of 4 (range, 1-7) prior chemotherapy regimens (Table 1).

Treatment

For the overall population, eribulin was administered for a median of two (range, 1-15) cycles, with seven patients receiving four or more cycles. For the individual dose groups $0.7,1.0,1.4$, and $2.0 \mathrm{mg} / \mathrm{m}^{2}$ eribulin mesylate, this was one (range, 1-2), two (range, 2-5), seven (range, 1-15), and five (range, 1-6) cycles, respectively. There were no dose delays, reductions, or omissions for patients who received the lowest dose of eribulin. For patients who 
Table 1 Baseline demographics and prior treatment of enrolled patients

Total $(N=15)$

\begin{tabular}{|c|c|}
\hline \multicolumn{2}{|l|}{ Age (years) } \\
\hline Median (range) & $58(40-73)$ \\
\hline \multicolumn{2}{|l|}{ Height $(\mathrm{cm})$} \\
\hline Mean SD & $163.0 \pm 7.13$ \\
\hline \multicolumn{2}{|l|}{ Weight $(\mathrm{kg})$} \\
\hline Mean SD & $64.0 \pm 8.50$ \\
\hline \multicolumn{2}{|c|}{ Body surface area $\left(\mathrm{m}^{2}\right)$} \\
\hline Mean SD & $1.642 \pm 0.13$ \\
\hline \multicolumn{2}{|l|}{ Gender, $n(\%)$} \\
\hline Male & $9(60.0)$ \\
\hline Female & $6(40.0)$ \\
\hline \multicolumn{2}{|c|}{ ECOG performance status, $n(\%)$} \\
\hline 0 & $4(26.7)$ \\
\hline 1 & $11(73.3)$ \\
\hline \multicolumn{2}{|c|}{ Tumor type, $n(\%)$} \\
\hline NSCLC & $3(20.0)$ \\
\hline Breast & $2(13.3)$ \\
\hline Colorectal & $3(20.0)$ \\
\hline Biliary & $2(13.3)$ \\
\hline Other $^{\mathrm{a}}$ & $5(33.3)$ \\
\hline \multicolumn{2}{|c|}{ Previous treatment, $n(\%)$} \\
\hline Surgery & $13(86.7)$ \\
\hline Radiation & $9(60.0)$ \\
\hline Chemotherapy & $15(100.0)$ \\
\hline \multicolumn{2}{|c|}{ Prior chemotherapy regimens, $n(\%)$} \\
\hline Platinum & $9(60.0)$ \\
\hline Taxane & $7(46.7)$ \\
\hline Anthracycline & $6(40.0)$ \\
\hline \multicolumn{2}{|c|}{ No. of prior chemotherapy regimens, $n(\%)$} \\
\hline 1 & $2(13.3)$ \\
\hline 2 & $2(13.3)$ \\
\hline 3 & $2(13.3)$ \\
\hline 4 & $3(20.0)$ \\
\hline$\geq 5$ & $6(40.0)$ \\
\hline Median (range) & $4.0(1-7)$ \\
\hline
\end{tabular}

${ }^{a}$ Other tumor types include cervical, head and neck, liposarcoma, melanoma, and renal

received two or more treatment cycles, the start of the next cycle was delayed in one of three patients in the $1.0 \mathrm{mg} / \mathrm{m}^{2}$ group, three of five patients in the $1.4 \mathrm{mg} / \mathrm{m}^{2}$ group, and in two of two patients in the $2.0 \mathrm{mg} / \mathrm{m}^{2}$ group. One patient receiving $1.0 \mathrm{mg} / \mathrm{m}^{2}$ eribulin omitted the Day 8 dose on one occasion during the study. In the $1.4 \mathrm{mg} / \mathrm{m}^{2}$ group, the Day 8 dose was omitted once for two patients and twice for one patient during the study, while in the $2.0 \mathrm{mg} / \mathrm{m}^{2}$ group the Day 8 dose was omitted once, twice, and three or more times for one patient each.
DLTs

Five of 15 patients (33\%) experienced DLTs during the first cycle. This included two of six (33\%) patients receiving eribulin mesylate $1.4 \mathrm{mg} / \mathrm{m}^{2}$ (one patient experienced grade 4 neutropenia for 5 days and the other patient developed grade 3 febrile neutropenia that resulted in omission of the Day 8 dose). In addition, all three patients receiving the $2.0 \mathrm{mg} / \mathrm{m}^{2}$ dose experienced DLTs (one patient developed grade 4 neutropenia lasting 5 days and a second patient experienced grade 3 febrile neutropenia, meaning that neither patient received the Day 8 dose; administration of eribulin on Day 8 was also omitted for the third patient due to grade 3 neutropenia). There were no DLTs reported for the 0.7 or $1.0 \mathrm{mg} / \mathrm{m}^{2}$ dose levels during the first cycle, therefore, the MTD of eribulin mesylate was established as $2.0 \mathrm{mg} / \mathrm{m}^{2}$ when administered to Japanese patients on Days 1 and 8 of a 21-day cycle, and the recommended dose for Phase II studies was $1.4 \mathrm{mg} / \mathrm{m}^{2}$.

The median time from Day 1 to nadir in neutrophil count was 14 days for eribulin mesylate $1.4 \mathrm{mg} / \mathrm{m}^{2}$ (range, 11-14 days) and 8 days for eribulin mesylate $2.0 \mathrm{mg} / \mathrm{m}^{2}$ (range, 7-9 days), in which all patients received only their Day 1 dose. Febrile neutropenia was resolved following oral or i.v. antibiotic treatment. These neutropenic events were easily managed, and the median time to recovery from the nadir to grades 0 or 1 was 8 days $(95 \%$ confidence interval [CI]: 8.0, 9.0) for patients receiving eribulin on both Days 1 and 8 (number of events $=40$ ), and 11 days $(95 \%$ CI: 8.0 , 17.0) for patients receiving eribulin on Day 1 (number of events $=7$ ).

\section{ADRs}

Grades 2,3 , and 4 ADRs reported by $\geq 10 \%$ of patients are shown in Table 2. As would be expected, a higher number of toxicities were experienced by those patients receiving either 1.4 or $2.0 \mathrm{mg} / \mathrm{m}^{2}$ eribulin mesylate. Frequently observed non-hematologic ADRs, which were generally mild and manageable, included hyperglycemia, fatigue, alopecia, nausea ( $n=8$, all grade 1$)$, anorexia, liver enzyme elevations (one patient with hepatic metastases experienced grade 3 elevation of $\gamma$-glutamyltransferase), and increased C-reactive protein levels $(n=5$, all grade 1$)$. One patient experienced grade 3 peripheral neuropathy $\left(1.4 \mathrm{mg} / \mathrm{m}^{2}\right.$ group). Hematologic ADRs tended to be either grade 3 or 4 and included neutropenia, leukopenia, and lymphocytopenia. There were no dose discontinuations due to ADRs.

\section{PK}

The median i.v. injection time was 5.0 min (range, 5-6) in cycle 1, and 5.0 min (range 4-9) across all cycles. However, 
Table 2 Incidence of grades 2, 3, and 4 toxicities possibly related to study treatment reported by $\geq 10 \%$ of patients

\begin{tabular}{|c|c|c|c|c|c|c|c|c|c|c|c|c|c|}
\hline \multirow[b]{3}{*}{ Adverse event, $n$ (\%) } & \multicolumn{13}{|c|}{ Eribulin initial dose level $\left(\mathrm{mg} / \mathrm{m}^{2}\right)$} \\
\hline & \multicolumn{3}{|c|}{$0.7(n=3)$} & \multicolumn{3}{|c|}{$1.0(n=3)$} & \multicolumn{3}{|c|}{$1.4(n=6)$} & \multicolumn{3}{|c|}{$2.0(n=3)$} & \multirow[t]{2}{*}{ Overall $(N=15)$} \\
\hline & G2 & G3 & G4 & G2 & G3 & G4 & G2 & G3 & G4 & G2 & G3 & G4 & \\
\hline \multicolumn{14}{|c|}{$\begin{array}{l}\text { Blood \& lymphatic system } \\
\text { disorders }\end{array}$} \\
\hline Febrile neutropenia & 0 & 0 & 0 & 0 & 0 & 0 & 0 & 3 & 0 & 0 & 2 & 0 & 5 \\
\hline \multicolumn{14}{|l|}{$\begin{array}{l}\text { Metabolism \& nutritional } \\
\text { disorders }\end{array}$} \\
\hline Anorexia & 0 & 0 & 0 & 0 & 0 & 0 & 1 & 0 & 0 & 0 & 1 & 0 & 2 \\
\hline \multicolumn{14}{|l|}{ Nervous system disorders } \\
\hline Peripheral neuropathy & 0 & 0 & 0 & 0 & 0 & 0 & 0 & 1 & 0 & 1 & 0 & 0 & 2 \\
\hline \multicolumn{14}{|l|}{$\begin{array}{l}\text { Skin \& subcutaneous } \\
\text { tissue disorders }\end{array}$} \\
\hline Alopecia & 0 & N/A & $\mathrm{N} / \mathrm{A}$ & 0 & $\mathrm{~N} / \mathrm{A}$ & N/A & 2 & N/A & N/A & 1 & N/A & N/A & 3 \\
\hline \multicolumn{14}{|l|}{$\begin{array}{l}\text { General disorders \& } \\
\text { administration-site } \\
\text { conditions }\end{array}$} \\
\hline Fatigue & 1 & 0 & 0 & 0 & 0 & 0 & 1 & 1 & 0 & 1 & 1 & 0 & 5 \\
\hline Pyrexia & 0 & 0 & 0 & 0 & 0 & 0 & 1 & 0 & 0 & 1 & 0 & 0 & 2 \\
\hline \multicolumn{14}{|l|}{ Investigations } \\
\hline Neutropenia & 0 & 0 & 0 & 1 & 1 & 0 & 0 & 1 & 5 & 0 & 1 & 2 & 11 \\
\hline Leukopenia & 0 & 0 & 0 & 2 & 1 & 0 & 0 & 4 & 2 & 0 & 2 & 1 & 12 \\
\hline Lymphocytopenia & 0 & 1 & 0 & 2 & 0 & 0 & 1 & 2 & 0 & 1 & 0 & 0 & 7 \\
\hline Anemia & 0 & 1 & 0 & 0 & 0 & 0 & 2 & 0 & 0 & 1 & 0 & 0 & 4 \\
\hline Decreased hemoglobin & 0 & 1 & 0 & 0 & 0 & 0 & 2 & 0 & 0 & 2 & 0 & 0 & 5 \\
\hline Hyperglycemia & 0 & 0 & 0 & 1 & 0 & 0 & 4 & 0 & 0 & 1 & 0 & 0 & 6 \\
\hline Thrombocytopenia & 0 & 0 & 0 & 1 & 0 & 0 & 1 & 0 & 0 & 0 & 0 & 0 & 2 \\
\hline Increased AST & 0 & 0 & 0 & 0 & 0 & 0 & 0 & 0 & 0 & 2 & 0 & 0 & 2 \\
\hline Increased ALT & 0 & 0 & 0 & 0 & 0 & 0 & 1 & 0 & 0 & 1 & 0 & 0 & 2 \\
\hline
\end{tabular}

$A L T$ alanine aminotransferase, $A S T$ aspartate aminotransferase, $N A$ not applicable

PK analyses assumed an infusion time of $5 \mathrm{~min}$ for all patients. In PK analyses, eribulin concentrations and PK parameters were expressed as the free base, whereas the doses were expressed as the mesylate salt equivalent $(1 \mathrm{mg}$ eribulin mesylate salt is equivalent to $0.884 \mathrm{mg}$ eribulin free base).

Eribulin exhibited triphasic PK over the dosing range of $0.7-2.0 \mathrm{mg} / \mathrm{m}^{2}$ (Fig. 1a, Table 3). Using non-compartmental analysis, treatment with eribulin resulted in a long terminal half-life (36.4-59.9 h), a low systemic clearance $\left(1.32-2.37 \mathrm{~L} / \mathrm{h} / \mathrm{m}^{2}\right)$, and a high volume of distribution $\left(105.6-143.0 \mathrm{~L} / \mathrm{m}^{2}\right)$ suggestive of a slow elimination of eribulin from plasma. Eribulin exhibited consistent PK parameter estimates between the first and second i.v. doses administered on Days 1 and 8 of the first cycle at each dose level.

The relationships between eribulin dose and $\mathrm{C}_{\max }$ and $\mathrm{AUC}_{0-\mathrm{t}}$ values were also estimated using least-square means weighted by logarithmic error distribution of PK data from Day 1 (Fig. $1 \mathrm{~b}$ and c). $\mathrm{C}_{\max }$ and $\mathrm{AUC}$ values increased in approximately direct proportion to increased eribulin dose.

$\mathrm{AUC}_{0-\mathrm{t}}$ values and change in neutrophil count from baseline were fitted according to $\mathrm{E}_{\max }$ (Fig. 2). $\mathrm{C}_{\max }$ and $\mathrm{AUC}_{0-\mathrm{t}}$ values were correlated with the rate of decrease in neutrophil count and white blood cell count, but correlated less with changes in other hematologic values.

Urinary excretion of eribulin was minimal, with $5.01-12.88 \%$ of the administered dose eliminated in urine over a 72 -h period after a single dose (Table 3 ).

Antitumor activity

Tumor responses were evaluable by RECIST in 14 patients. Partial responses were achieved in three patients (two with NSCLC and one with head and neck cancer) at the $1.4 \mathrm{mg} / \mathrm{m}^{2}$ dose level. All of these patients had previously undergone 

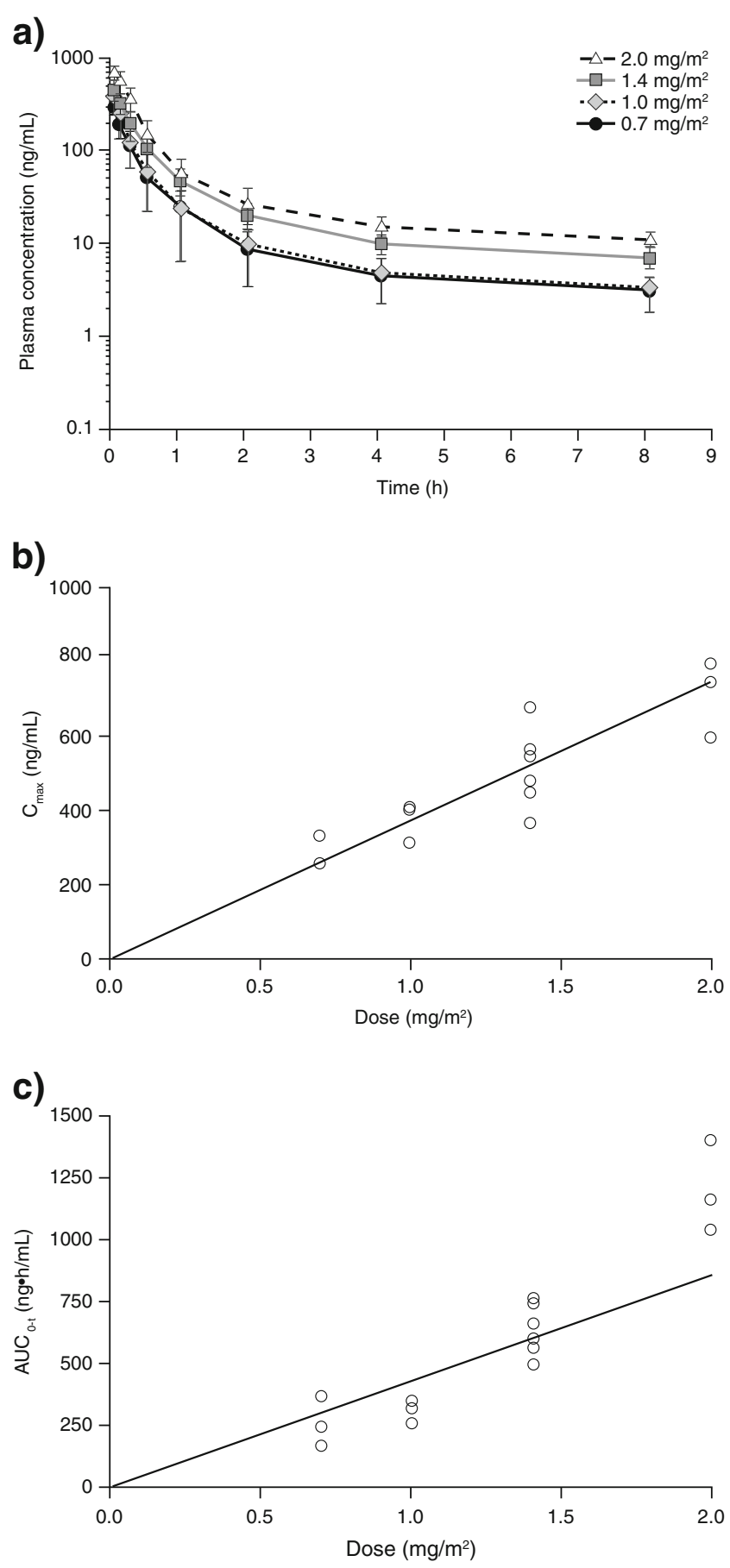

Fig. 1 PK analysis of enrolled patient population: a relationship between plasma concentration versus time profiles for each eribulin dose group; $\mathbf{b}$ relationship between $\mathrm{C}_{\max }$ versus dose following a 2- to 10-min injection of eribulin on Day 1; and $\mathbf{c}$ relationship between $\mathrm{AUC}_{0-\mathrm{t}}$ versus dose following a 2- to 10 -min injection of eribulin on Day 1

surgical therapy and had received at least three prior chemotherapy regimens. Stable disease was observed in four patients (two with breast cancer, one with biliary cancer, and one with cervical cancer); for two of these patients, the duration of stable disease was greater than 24 weeks. Two patients were treated at the $2.0 \mathrm{mg} / \mathrm{m}^{2}$ dose level and one each at the 1.0 and $1.4 \mathrm{mg} / \mathrm{m}^{2}$ eribulin dose levels.

\section{Discussion}

This Phase I study established the recommended dose of $1.4 \mathrm{mg} / \mathrm{m}^{2}$ eribulin mesylate i.v. injection when administered on Days 1 and 8 of a 21-day cycle in Japanese patients with advanced solid tumors. MTD was $2.0 \mathrm{mg} / \mathrm{m}^{2}$, and the main DLT was neutropenia, which was easily managed.

The most common AEs of grade 3 or higher reported in this study were neutropenia and leukopenia, which are hematologic toxicities in common with taxanes [15]. The analysis presented here demonstrates that the rates of decrease of neutrophil and white blood cell count correlate with the $\mathrm{C}_{\max }$ and $\mathrm{AUC}_{0-\mathrm{t}}$ of eribulin. The AEs classified as DLTs were neutropenia and febrile neutropenia. At the recommended dose of eribulin determined by this study of $1.4 \mathrm{mg} / \mathrm{m}^{2}$, all six patients experienced neutropenia; however, all events were reversible and easily managed. Indeed, the schedule of administering eribulin on Days 1 and 8 of a 21-day cycle is supported by the median time required for resolution of $\geq$ grade 3 neutropenia to grade 1 or lower.

The reported non-hematologic AEs are consistent with the known tolerability profile of eribulin, with fatigue being the most common non-hematologic $\mathrm{AE}$ of grade 3 or higher. One patient experienced grade 3 anorexia and one patient experienced grade 3 peripheral neuropathy. Other non-hematologic AEs included hyperglycemia, alopecia, nausea, elevated liver enzymes, and increased C-reactive protein levels; however, these AEs were predominantly mild (grade 1 or 2) and manageable. Although efficacy was not a primary objective, 3 out of 14 evaluable patients experienced partial responses (all in the $1.4 \mathrm{mg} / \mathrm{m}^{2}$ dose group).

The results reported here are in agreement with the safety, MTD, DLT, AE, and ADR profiles reported in previous Phase I studies [6-8]. All three prior Phase I trials cited neutropenic events as the main DLTs, despite variations in the administration and dosages of eribulin, and most ADRs were grade 2 or less across all doses tested. Myelosuppression and fatigue were the most commonlyreported AEs attributed to eribulin, and no hypersensitivity reactions occurred. In addition, incidences of neuropathy were low, which is an important and significant point of distinction between eribulin and either taxanes or epothilones $[6-8,15,16]$ because patients in these studies were heavily pretreated and the severity of neuropathy tends to be cumulative. 
Table 3 PK analyses on Day 1

Ae, amount of unchanged drug excreted in urine; $\mathrm{AUC}_{0 \text {-inf, }}$, area under the concentration-time curve from time zero to infinity; $\mathrm{CL}$, total clearance; $\mathrm{CL}_{\mathrm{R}}$, renal clearance; fe, fraction of the dose excreted unchanged in the urine; MRT, mean residence time; $t_{1 / 2}$, final elimination halflife; $\mathrm{V}_{\mathrm{z}}$, volume of distribution at terminal phase

\begin{tabular}{|c|c|c|c|c|}
\hline Parameter (mean $\pm \mathrm{SD})$ & $0.7 \mathrm{mg} / \mathrm{m}^{2}(n=3)$ & $1.0 \mathrm{mg} / \mathrm{m}^{2}(n=3)$ & $1.4 \mathrm{mg} / \mathrm{m}^{2}(n=6)$ & $2.0 \mathrm{mg} / \mathrm{m}^{2}(n=3)$ \\
\hline \multicolumn{5}{|l|}{ Plasma } \\
\hline $\mathrm{C}_{\max }(\mathrm{ng} / \mathrm{mL})$ & $288.5 \pm 43.0$ & $380.6 \pm 52.9$ & $519.4 \pm 107.2$ & $717.6 \pm 104.3$ \\
\hline $\mathrm{AUC}_{0-\text { inf }}(\mathrm{ng} \cdot \mathrm{h} / \mathrm{mL})$ & $299.2 \pm 124.5$ & $379.6 \pm 65.2$ & $672.7 \pm 113.7$ & $1370.1 \pm 282.2$ \\
\hline$t_{1 / 2}(h)$ & $36.4 \pm 11.2$ & $42.9 \pm 10.9$ & $39.4 \pm 8.3$ & $59.9 \pm 13.4$ \\
\hline $\mathrm{CL}\left(\mathrm{L} / \mathrm{h} / \mathrm{m}^{2}\right)$ & $2.31 \pm 0.88$ & $2.37 \pm 0.39$ & $1.89 \pm 0.33$ & $1.32 \pm 0.25$ \\
\hline $\mathrm{V}_{\mathrm{z}}\left(\mathrm{L} / \mathrm{m}^{2}\right)$ & $117.3 \pm 45.0$ & $143.0 \pm 14.4$ & $105.6 \pm 19.6$ & $111.7 \pm 13.0$ \\
\hline MRT (h) & $32.6 \pm 9.1$ & $40.8 \pm 10.4$ & $40.7 \pm 10.1$ & $67.5 \pm 22.5$ \\
\hline \multicolumn{5}{|l|}{ Urine } \\
\hline $\mathrm{Ae}(\mu \mathrm{g})$ & $51.9 \pm 8.89$ & $104.5 \pm 31.9$ & $238.1 \pm 28.4$ & $355.7 \pm 98.7$ \\
\hline fe $(\%)$ & $5.01 \pm 0.69$ & $7.36 \pm 2.47$ & $11.52 \pm 1.04$ & $12.88 \pm 3.95$ \\
\hline $\mathrm{CL}_{\mathrm{R}}(\mathrm{mL} / \mathrm{h})$ & $220.5 \pm 62.7$ & $352.2 \pm 127.2$ & $454.4 \pm 83.6$ & $394.8 \pm 94.2$ \\
\hline $\mathrm{CL}(\mathrm{mL} / \mathrm{h})$ & $3808.8 \pm 1295.4$ & $3872.5 \pm 807.0$ & $3126.3 \pm 416.0$ & $2086.3 \pm 441.7$ \\
\hline
\end{tabular}

The PK parameters of eribulin administered at various dosing schedules were also consistent between this study and the three previously reported Phase I trials, including the mean terminal half-life, volume of distribution, and renal and systemic clearance, and, as in these studies, parameters were consistent between Days 1 and 8 of the first cycle [6-8]. The studies reported by Goel et al. [7] and Tan et al. [8] concluded that the PK of eribulin exhibited a biphasic elimination pattern, whereas a triphasic elimination pattern was reported in both the current study and the study reported by Synold et al [6]. This study, as well as those reported by Goel et al and Tan et al. [6-8], suggests that urinary excretion is a minor route of eribulin clearance. The prolonged half-life of eribulin, coupled with its large volume of distribution and low urinary excretion, suggest the advantage of longer exposure to the antitumor activity of eribulin.

Three Phase II trials have now investigated eribulin mesylate $1.4 \mathrm{mg} / \mathrm{m}^{2}$ administered on Days 1 and 8 of a 21-day cycle in extensively pre-treated patients with MBC $[9,17,18]$. Consistent with the present study, the most

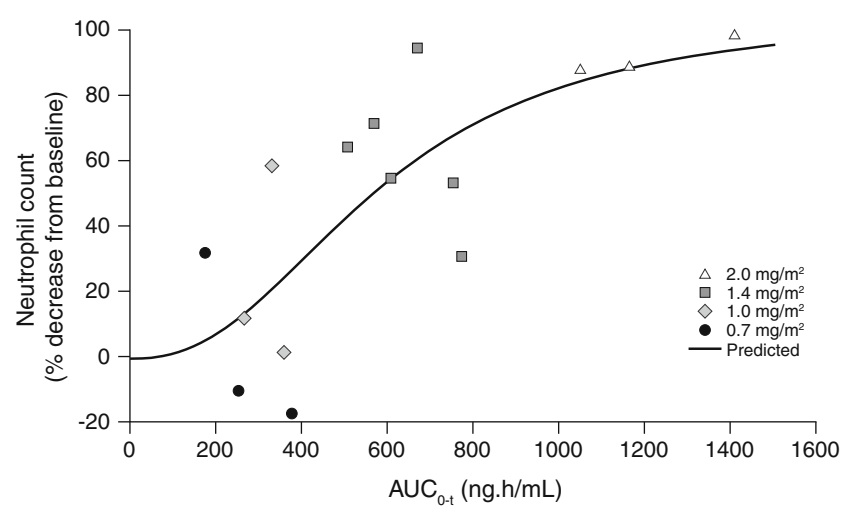

Fig. $2 \mathrm{AUC}_{0-\mathrm{t}}$ on Day 1 and decrease in neutrophil count from baseline fitted according to $\mathrm{E}_{\max }$ frequently reported grade $3 / 4$ treatment-related toxicities in these Phase II trials were neutropenia, febrile neutropenia, leukopenia, and fatigue, and the incidence of grade $3 / 4$ neuropathy was low. Moreover, a Phase II study involving patients with NSCLC cited neutropenia and fatigue as the most common drug-related AEs associated with eribulin mesylate $1.4 \mathrm{mg} / \mathrm{m}^{2}$ administered on Days 1 and 8 of a 21-day cycle [10]. One of these Phase II studies has been conducted in heavily pre-treated Japanese patients with MBC and reported preliminary results of an overall response rate of $21.3 \%$ and clinical benefit rate of $27.5 \%$ [18].

Furthermore, results have recently been reported from the global Phase III EMBRACE study of eribulin in heavily pre-treated patients with $\mathrm{MBC}$, which used the same dose and administration schedule investigated in our Phase I study. A significant increase in median overall survival was observed with eribulin compared with treatment of physician's choice (TPC) (hazard ratio $0.81 ; 95 \%$ CI: $0.66,0.99$; $P=0.041$ ) [19]. The most common AEs in both groups were asthenia or fatigue (54\% with eribulin; $40 \%$ with TPC [all grades]) and neutropenia (52\% with eribulin; 30\% with TPC [all grades]). Based on the results of this study, eribulin has received approval in the US, Singapore and from the European Commission for the treatment of patients with $\mathrm{MBC}$ who have previously received at least two chemotherapeutic regimens for the treatment of metastatic disease. Prior therapy should have included an anthracycline and a taxane in either the adjuvant or metastatic setting. More recently, eribulin has received approval in Japan for the treatment of patients with inoperable or recurrent breast cancer, who have received prior chemotherapy including an anthracycline and a taxane, and have progressed or relapsed since their last chemotherapeutic regimen.

In conclusion, eribulin mesylate $1.4 \mathrm{mg} / \mathrm{m}^{2}$ administered on Days 1 and 8 of a 21-day cycle was found to exhibit 
manageable tolerability, with further dose escalation limited by neutropenia, in the current study in Japanese patients with advanced solid tumors. These findings have helped establish the recommended dosing schedule of eribulin in MBC that has now been approved in the US, Singapore, Japan and by the European Commission.

Acknowledgments We gratefully acknowledge the commitment of participating patients, their families, and the study investigators for their invaluable contribution to this research. Medical writing support was provided by Sarah Feaver, $\mathrm{PhD}$, at Complete Medical Communications and was funded by Eisai Inc.

Disclosures This work was supported by funding from Eisai Co., Ltd. Hironobu Minami serves as a consultant to Eisai Co., Ltd. Masayuki Namiki is employed by Eisai Co., Ltd. Toru Mukohara, Hirofumi Mukai and Shunji Nagai have no disclosures.

Open Access This article is distributed under the terms of the Creative Commons Attribution Noncommercial License which permits any noncommercial use, distribution, and reproduction in any medium, provided the original author(s) and source are credited.

\section{References}

1. Kuznetsov G, Towle MJ, Cheng H, Kawamura T, TenDyke K, Liu D, Kishi Y, Yu MJ, Littlefield BA (2004) Induction of morphological and biochemical apoptosis following prolonged mitotic blockage by halichondrin B macrocyclic ketone analog E7389. Cancer Res 64:5760-5766

2. Towle MJ, Salvato KA, Budrow J, Wels BF, Kuznetsov G, Aalfs KK, Welsh S, Zheng W, Seletsky BM, Palme MH, Habgood GJ, Singer LA, Dipietro LV, Wang Y, Chen JJ, Quincy DA, Davis A, Yoshimatsu K, Kishi Y, Yu MJ, Littlefield BA (2001) In vitro and in vivo anticancer activities of synthetic macrocyclic ketone analogues of halichondrin B. Cancer Res 61:1013-1021

3. Jordan MA, Kamath K, Manna T, Okouneva T, Miller HP, Davis C, Littlefield BA, Wilson L (2005) The primary antimitotic mechanism of action of the synthetic halichondrin E7389 is suppression of microtubule growth. Mol Cancer Ther 4:1086-1095

4. Okouneva T, Azarenko O, Wilson L, Littlefield BA, Jordan MA (2008) Inhibition of centromere dynamics by eribulin (E7389) during mitotic metaphase. Mol Cancer Ther 7:2003-2011

5. Dabydeen DA, Burnett JC, Bai R, Verdier-Pinard P, Hickford SJ, Pettit GR, Blunt JW, Munro MH, Gussio R, Hamel E (2006) Comparison of the activities of the truncated halichondrin $\mathrm{B}$ analog NSC 707389 (E7389) with those of the parent compound and a proposed binding site on tubulin. Mol Pharmacol 70:1866-1875

6. Synold TW, Morgan RJ, Newman EM, Lenz HJ, Gandara DR, Colevas HD, Lewis MD, Doroshow JH (2005) A phase I pharmacokinetic and target validation study of the novel antitubulin agent E7389: a California Cancer consortium trial [abstract 3036]. J Clin Oncol 23:3036

7. Goel S, Mita AC, Mita M, Rowinsky EK, Chu QS, Wong N, Desjardins C, Fang F, Jansen M, Shuster DE, Mani S, Takimoto C (2009) A Phase I study of eribulin mesylate (E7389), a mechanistically novel inhibitor of microtubule dynamics, in patients with advanced solid tumors. Clin Cancer Res $15: 4207-4212$

8. Tan AR, Rubin EH, Walton DC, Shuster DE, Wong NY, Fang F, Ashworth S, Rosen LS (2009) Phase I study of eribulin mesylate (E7389) administered once every 21 days in patients with advanced solid tumors. Clin Cancer Res 15:4213-4218

9. Vahdat LT, Pruitt B, Fabian CJ, Rivera RR, Smith DA, Tan-Chiu E, Wright J, Tan AR, Dacosta NA, Chuang E, Smith J, O'Shaughnessy J, Shuster DE, Meneses NL, Chandrawansa K, Fang F, Cole PE, Ashworth S, Blum JL (2009) Phase II study of eribulin mesylate, a halichondrin $\mathrm{B}$ analog, in patients with metastatic breast cancer previously treated with an anthracycline and a taxane. J Clin Oncol 27:2954-2961

10. Spira AI, Iannotti NO, Savin MA, Neubauer M, Gabrail NY, Yanagihara R, Datta KK, Zang EA, Das A (2007) Phase II study of eribulin mesylate (E7389), a mechanistically novel inhibitor of microtubule dynamics, in patients with advanced non-small cell lung cancer (NSCLC) [abstract 7546]. J Clin Oncol 25:396s

11. Zhang ZY, King BM, Pelletier RD, Wong YN (2008) Delineation of the interactions between the chemotherapeutic agent eribulin mesylate (E7389) and human CYP3A4. Cancer Chemother Pharmacol 62:707-716

12. (2004) [Japanese translation of common terminology criteria for adverse events (CTCAE), and instructions and guidelines]. Int $\mathrm{J}$ Clin Oncol 9(Suppl 3):1-82

13. Desjardins C, Saxton P, Lu SX, Li X, Rowbottom C, Wong YN (2008) A high-performance liquid chromatography-tandem mass spectrometry method for the clinical combination study of carboplatin and antitumor agent eribulin mesylate (E7389) in human plasma. J Chromatogr B Analyt Technol Biomed Life Sci 875:373-382

14. Therasse P, Arbuck SG, Eisenhauer EA, Wanders J, Kaplan RS, Rubinstein L, Verweij J, Van Glabbeke M, van Oosterom AT, Christian MC, Gwyther SG (2000) New guidelines to evaluate the response to treatment in solid tumors. European Organization for Research and Treatment of Cancer, National Cancer Institute of the United States, National Cancer Institute of Canada. J Natl Cancer Inst 92:205-216

15. Markman M (2003) Management of toxicities associated with the administration of taxanes. Expert Opin Drug Saf 2:141-146

16. Steinberg M (2008) Ixabepilone: a novel microtubule inhibitor for the treatment of locally advanced or metastatic breast cancer. Clin Ther 30:1590-1617

17. Cortes J, Vahdat L, Blum JL, Twelves C, Campone M, Roche H, Bachelot T, Awada A, Paridaens R, Goncalves A, Shuster DE, Wanders J, Fang F, Gurnani R, Richmond E, Cole PE, Ashworth S, Allison MA (2010) Phase II study of the halichondrin B analog eribulin mesylate in patients with locally advanced or metastatic breast cancer previously treated with an anthracycline, a taxane, and capecitabine. J Clin Oncol 28:3922-3928

18. Iwata H, Aogi K, Masuda N, Mukai H, Yoshida M, Rai Y, Taguchi K, Sasaki Y, Takashima S (2010) Efficacy and safety of eribulin in Japanese patients (pts) with advanced breast cancer [abstract 1081]. J Clin Oncol 28:15s

19. Cortes J, O'Shaughnessy J, Loesch D, Blum JL, Vahdat LT, Petrakova K, Chollet P, Manikas A, Dieras V, Delozier T, Vladimirov V, Cardoso F, Koh H, Bougnoux P, Dutcus CE, Seegobin S, Mir D, Meneses N, Wanders J, Twelves C (2011) Eribulin monotherapy versus treatment of physician's choice in patients with metastatic breast cancer (EMBRACE): a phase 3 open-label randomised study. Lancet 377:914-923 